\section{Commentary: The Ross procedure: One surgeon's journey toward mastery}

\author{
Vincent Chauvette, MD, ${ }^{a, b}$ \\ Maral Ouzounian, MD, $\mathrm{PhD},{ }^{c}$ \\ Mark D. Peterson, MD, PhD, ${ }^{\mathrm{c}, \mathrm{c}}$ \\ Ismail El-Hamamsy, $\mathrm{MD}, \mathrm{PhD},{ }^{\mathrm{e}}$ and \\ Michael W. A. Chu, MD, MEd, ${ }^{\text {a }}$ on behalf of the \\ Canadian Thoracic Aortic Collaborative
}

Stelzer and colleagues ${ }^{1}$ present a study looking at the outcomes of more than 700 patients who underwent a Ross procedure over a 30 -year period. Although the number of patients undergoing operation by a single surgeon during this time period is in itself an achievement, the perioperative outcomes described in this article speak of the mastery that one can achieve with dedication to this procedure. Indeed, whereas the Ross procedure was once seen as a high-risk operation reserved for very select patients, there has been renewed interest for this aortic valve replacement (AVR) option in recent years. In fact, multiple groups have recently published excellent mid- and long-term outcomes associated with this procedure. ${ }^{2-5}$ Although the field of AVR in low-risk patients is becoming increasingly complex, the Ross procedure stands out as the only option that preserves the viability

From the ${ }^{\text {a Division }}$ of Cardiac Surgery, Department of Surgery, Western University, London, Ontario, Canada; ${ }^{\mathrm{b}}$ Division of Cardiac Surgery, Department of Surgery, University of Montreal, Montreal, Québec, Canada; ' Division of Cardiac Surgery, Department of Surgery, University of Toronto, Toronto, Ontario, Canada; ${ }^{\mathrm{d} D i v i s i o n}$ of Cardiac Surgery, Department of Surgery, St Michael's Hospital, Toronto, Ontaio, Canada; and ${ }^{\mathrm{e} D e p a r t m e n t ~ o f ~ C a r d i o v a s c u l a r ~ S u r g e r y, ~ M o u n t ~ S i n a i ~ H o s p i t a l ~}$ and Icahn School of Medicine at Mount Sinai, New York, NY.

Disclosures: Dr Chu has received speaker's honoraria from Medtronic, Edwards Lifesciences, Terumo Aortic, and Cryolife. Dr Ouzounian has received speaker's honoraria from Medtronic, Edwards Lifesciences, and Cryolife. All other authors reported no conflicts of interest.

The Journal policy requires editors and reviewers to disclose conflicts of interest and to decline handling or reviewing manuscripts for which they may have a conflict of interest. The editors and reviewers of this article have no conflicts of interest.

Received for publication Dec 8, 2020; revisions received Dec 8, 2020; accepted for publication Dec 9, 2020; available ahead of print Dec 22, 2020.

Address for reprints: Michael W. A. Chu, MD, MEd, Division of Cardiac Surgery, Department of Surgery, Western University, B6-106 University Hospital, London Health Sciences Centre, 339 Windermere Rd, London, Ontario N6A 5A5, Canada (E-mail: Michael.Chu@1hsc.on.ca).

J Thorac Cardiovasc Surg 2021;161:918-9

$0022-5223 / \$ 36.00$

Copyright (c) 2020 by The American Association for Thoracic Surgery

https://doi.org/10.1016/j.jtcvs.2020.12.056

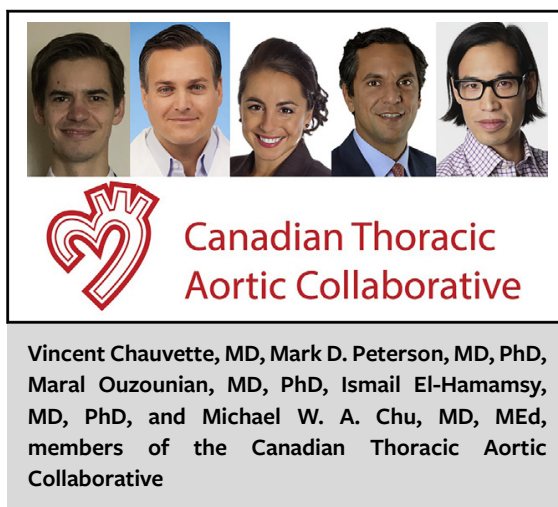

CENTRAL MESSAGE

The Ross procedure can be performed with surgical risk similar

to standard AVR. However, mastery takes a dedicated career of reassessment focused on quality improvement to achieve optimal results.

of the aortic root. This has profound influence on quality of life, exercise tolerance, hemodynamic parameters, and long-term survival. In nonelderly patients with a life expectancy $>15$ years, these features are of the utmost importance for optimal long-term care. Thus, as some authors have suggested, the Ross procedure may be the best AVR option in this population, provided that it can be offered with similar risk to that of a standard AVR. ${ }^{6}$ In this regard, the article from Stelzer and colleagues ${ }^{1}$ strongly supports the idea that dedicated surgeons can perform the Ross procedure, with low perioperative morbidity, even in complex cases such as active endocarditis or reoperation. Although critics may argue that the results from this study are those of a single, highly experienced surgeon, a number of studies (both single and multicenter) have now demonstrated similar outcomes in institutions with dedicated Ross programs. ${ }^{3,4}$

Similar to complex aortic root surgery or mitral repair, this study also reinforces that patients eligible for the Ross procedure should be referred to centers of excellence for evaluation and management. Patients should be presented with all options to make an informed decision regarding the ideal treatment for their valve dysfunction that is not limited by the offerings of the surgeon seated before them. Ultimately, the decision must be tailored to each individual patient, taking into consideration 
comorbidities, anatomical details, degree of physical activity, risk of reintervention, life expectancy, and a patient's personal values.

Alternatively, experienced, high-volume aortic root surgeons might start Ross programs, provided adequate mentorship can be obtained. Doing do would require concerted efforts from various surgical societies to train a new generation of surgeons in reconstructive aortic root surgery, as well as defining benchmarks for centers of aortic excellence, as has been done for mitral surgery.

The Ross procedure remains a more complex procedure than a standard AVR. In this study, including $15 \%$ of patients with prior sternotomy, Stelzer and colleagues ${ }^{1}$ report an overall perioperative mortality of $1 \%$, very similar to the risk associated with standard AVR. ${ }^{7}$ Because it focused on short-term outcomes, it is impossible to ascertain from this report whether the pulmonary autograft held its promises in the long-term. Nevertheless, multiple groups have reported on the excellent long-term outcomes associated with this surgical option. ${ }^{2,8,9}$ The Ross procedure is the only AVR option consistently associated with survival similar to that of an age- and sex-matched population. ${ }^{2-4}$ This is in stark contrast with the excess in late mortality associated with bioprosthetic and mechanical valves. ${ }^{10-12}$ However, as is highlighted by Stelzer and colleagues, ${ }^{1}$ excellent outcomes require dedication and career-long adaptation to perfect surgical techniques. Their honest account in sharing outcomes, lessons learned, and the potential pitfalls one may encounter when performing a Ross procedure are invaluable. Perfection remains an aspirational (and often elusive) goal, but learning from others' lifelong commitment to achieve technical mastery of the Ross procedure brings us one step closer.

\section{References}

1. Stelzer P, Mejia J, Varghese R. Operative risks of the Ross procedure. J Thorac Cardiovasc Surg. 2021;161:905-15.e3.

2. David TE, Ouzounian M, David CM, Lafreniere-Roula M, Manlhiot C. Late results of the Ross procedure. J Thorac Cardiovasc Surg. 2019;157:201-8.

3. Chauvette V, Bouhout I, Tarabzoni M, Wong D, Bozinovski J, Chu MWA, et al. The Ross procedure in patients older than 50: a sensible proposition? J Thorac Cardiovasc Surg. October 6, 2020 [Epub ahead of print].

4. Sievers H-H, Stierle U, Charitos EI, Takkenberg JJM, Hörer J, Lange R, et al. A multicentre evaluation of the autograft procedure for young patients undergoing aortic valve replacement: update on the German Ross Registry. Eur J Cardiothorac Surg. 2015;49:212-8.

5. Buratto E, Shi WY, Wynne R, Poh CL, Larobina M, O'Keefe M, et al. Improved survival after the Ross procedure compared with mechanical aortic valve replacement. J Am Coll Cardiol. 2018;71:1337-44.

6. Ouzounian M, Mazine A, David TE. The Ross procedure is the best operation to treat aortic stenosis in young and middle-aged adults. J Thorac Cardiovasc Surg. 2017; $154: 778-82$.

7. Brown JM, O'Brien SM, Wu C, Sikora JAH, Griffith BP, Gammie JS. Isolated aortic valve replacement in North America comprising 108,687 patients in 10 years: changes in risks, valve types, and outcomes in the Society of Thoracic Surgeons National database. J Thorac Cardiovasc Surg. 2009;137:82-90.

8. Mastrobuoni S, de Kerchove L, Solari S, Astarci P, Poncelet A, Noirhomme P, et al. The Ross procedure in young adults: over 20 years of experience in our Institution. Eur J Cardiothorac Surg. 2015;49:507-13.

9. Poh CL, Buratto E, Larobina M, Wynne R, O'Keefe M, Goldblatt J, et al. The Ross procedure in adults presenting with bicuspid aortic valve and pure aortic regurgitation: $85 \%$ freedom from reoperation at 20 years. Eur J Cardiothorac Surg. 2018;54:420-6.

10. Goldstone AB, Chiu P, Baiocchi M, Lingala B, Patrick WL, Fischbein MP, et al Mechanical or biologic prostheses for aortic-valve and mitral-valve replacement. N Engl J Med. 2017;377:1847-57.

11. Bourguignon T, Lhommet P, El Khoury R, Candolfi P, Loardi C, Mirza A, et al Very long-term outcomes of the Carpentier-Edwards Perimount aortic valve in patients aged 50-65 years. Eur J Cardiothorac Surg. 2016;49:1462-8.

12. Kvidal P, Bergström R, Hörte LG, Ståhle E. Observed and relative survival after aortic valve replacement. J Am Coll Cardiol. 2000;35:747-56. 